LETTERS TO THE EDITOR

\section{Culture of safety}

Congratulations to Singer et al for the comprehensive survey of safety culture performed in 15 hospitals. The overall response rate of only $47.4 \%$ was largely due to the poor response by physicians (33\%). Efforts need to be taken to increase the response rate to achieve a more reliable result. Most of the participants in the survey responded in ways which indicated a culture of safety. However, it would be interesting to determine the safety culture in hospitals which do not belong to the "hospitals participating in the California Patient Safety Consortium" group. It is noted that higher responses are attributable to shorter survey questions. People are generally not interested if they have to go through a large format. Clinicians, as expected, were more critical about the patient care safety and thus scored more "problematic responses". The survey sample noted that a total of 6312 eligible individuals participated. That figure is actually 6332 individuals (initial mailing list of 6909 names minus 347 duplicates minus 227 undeliverable $=6332$ ). The high percentage of non-respondents (an overall figure of $53 \%$ ) could possibly still lead to non-response bias. A survey of the non-responders would be interesting.

Senior managers gave fewer problematic responses than frontline workers. Generally speaking, all senior managers will want to give a high opinion of their own organization/ institution. In addition, they may not have been briefed about the patient care problems

Using the High Reliability Organization (HRO) standard cut off point of $10 \%$ problematic attitudes, the results of an overal problematic response of $13 \%$ is worrying. Generally it can be assumed that we still need to improve and to internalize the culture of safety in healthcare settings among all levels of healthcare workers. A culture of safety should be instilled into all healthcare workers from their undergraduate student days if it is to be internalized within ourselves. Stevens emphasises that "improving health and health care begins with the focus on improving medical education".

Davidoff ${ }^{3}$ raises another important point when he states that "bringing issues of quality and safety out of the shadows can remove some of the sting associated with improvement". Who can doubt that the real agenda in the controversy currently raging over mandatory reporting of medical errors is the fear of being ashamed? The results of this study also support this-problematic responses were higher for questions that were phrased as hypothetical or impersonal and lower for questions that were personal or time delimited. It would be interesting to adapt and conduct a similar survey on the culture of safety in our own healthcare institutions and to compare the findings using the results obtained by Singer $e t$ al as a baseline measure

N K S Vengadasalam Medical Hospital Sik, Malaysia dr_nesa@hotmail.com
References

Singer S, Gaba DM, Geppert JJ, et al. The culture of safety: results of an organization-wide survey in 15 California hospitals. Qual Saf Health Care 2003;12:112-8

2 Stevens DP. Finding safety in medical education. Qual Saf Health Care 2002:11:109-110

3 Davidoff F. Shame: the elephant in the room. Qual Saf Health Care 2002;11:2-3.

We welcome Singer and colleague's contribution to developing the concept of a safety culture. ${ }^{1}$ Policy makers, managers, and clinicians are slowly realising that patient safety will not be improved solely by counting adverse events or by introducing technical innovations. History tells us that, when these initiatives are evaluated, the results will probably show a marginal impact on patient safety and one that is likely to be poorly sustained. In order to maximise their impact we need to understand the shared attitudes, beliefs, values, and assumptions that underlie how people perceive and act upon safety issues within their organisations. This is what is commonly called the "safety culture" of an organisation.

The problem with the approach adopted in this paper is that it fails to get to the heart of the hospital's culture. What they have done is to use a blunt survey instrument to assess the opinions of individual members of staff to a series of statements about safety. The responses represent the most superficial evaluation of the "climate" of the organisations in which they work. These opinions are likely to be influenced by a wide range of factors that have little to do with the organisation's culture. Furthermore, the relationship between these opinions and the shared values that underlie them is largely unknown.

If we really want to understand the safety culture of an organisation, we need to use more sophisticated approaches. ${ }^{2}$ These should draw on a wide range of methodsparticipant observation, in-depth and semistructured interviews and focus groups, together with attitudinal surveys and the use of new and established culture measurement tools. ${ }^{3}$ Developmental or action research approaches might provide additional insights into the complexity of the organisations. The aim should be not only to understand and assess the concept of safety culture, but also to examine ways of improving it and integrating it with the broader field of organisational culture. This presents a significant challenge to health service researchers. Singer and colleagues have made a start, but there is a long way to go before we know how-or, indeed, whether-it is possible to change the safety culture of our hospitals and primary care centres.

M Marshall, D Parker, A Esmail, S Kirk, T Claridge Institute for Health Sciences, University of Manchester, Manchester M13 9PL, UK martin.marshall@man.ac.uk

\section{References}

1 Singer S, Gaba DM, Geppert JJ, et al. The culture of safety: results of an organization-wide survey in 15 California hospitals. Qual Saf Health Care 2003;12:112-8.
2 Mannion R, Davies H, Marshall M. Cultures for performance in health care: evidence on the relationships between organisational culture and organisational performance in the NHS. York: Centre for Health Economics, 2003

3 Scott J, Mannion R, Marshall M, et al. The quantitative measurement of organisational culture in health care: a review of the available instruments. Health Serv Res 2003 (in press).

\section{BOOK REVIEWS}

\section{Quantifying Quality in Primary} Care

Edited by Peter Graves. Abingdon, Oxon: Radcliffe Medical Press, 2002. $£ 32.95$ 257 pp. ISBN 1857755995

It is always helpful to have a checklist for any task, whether it is for simply preparing to go on an overseas trip or something as complex as ensuring a high quality service for patients in primary care. It is even better if someone as experienced as Peter Graves has compiled one for you, which can be the basis of your own tailor-made solution.

Clinical governance is at the heart of this book, but many sources are used to inform its content such as NHS (GMS) regulations, Health and Safety at Work laws, and the GMC's views on Good Medical Practice. The main areas that are addressed are "The Patient's Experience", "Patient Management and Treatment", and "Practice Management", and if all three are right then the aim of good patient care and outcomes will be achieved The charts and scoring system are consistent and very sensible. The layout is clear and the questions are realistic, with a range of scores possible that will help practices understand their current position and enable them to plan for improvement.

Few will take the whole content on board but, as a basis for assessing even just a few areas where weakness is perceived, the order and common sense brought to the process will be rewarding.

D Empey

Rapid Response Unit, National Clinical Governance Support Team, NHS Modernisation Agency; duncan.empey@bartsandthelondon.nhs.uk

\section{Getting Health Economics into Practice}

Kernick D, ed. Abingdon, Oxon: Raddlife Medical Press, 2002. Pp 324. ISBN 185775 5758

It was with a somewhat heavy heart that I accepted the challenge to write a review of an economics book. Although I knew the editor wrote well, a book on economics was not at the top of my reading list. It would do me some good, I thought. In the end it wasn't a challenge-I read the book in two weeks, enjoying the punchy, well written text, andyes-it did me good. But unlike many self-betterment schemes, it was painless.

What stood out were the clear aims at the start of the book and the introductions to each section and to most chapters. Sometimes this 
can be laboured (tell them what you're going to say, say it, and then tell them what you said). On this occasion it felt as if it worked in a coherent manner, and aided me to understand better the text and where the following chapter fitted in with the big scheme of economic things.

For much of the book I was introduced to new ideas that helped me think about how health care could work. Sometimes, though, the book gave words to issues that are often discussed in the "hurly burly" of health care (the "swamp lands", as David Kernick puts it). For instance, the concepts of moral hazard (where someone doesn't have to pay for a service) and principal agent (where someone carries out a task on behalf of others) were particularly helpful. Chapters on well worn issues like the transfer of activity to primary care and skill mix also breathed new life into areas I had stopped properly thinking about.

Criticisms? Very few. The book is too focused on primary care. Although it is relevant to the whole of health care, the examples belie the editor's roots which might wrongly limit its appeal to other readers. Astonishingly, I found some of the chapters too brief. I cannot decide whether this was a fault of the book or whether it has whetted my appetite to look further. Although the book was well laid out, sometimes the connections between the chapters were not clear and they were lumped together in a section that might more appropriately be considered miscellaneous. But this is nit picking. Inevitably in a multi-authored book there was repetition, but even this was generally helpful to an ignorant reader like myself, especially because-where it occurred-it was thankfully consistent (good editing I presume).

In their instructions QSHC asks book reviewers not to end with the well worn phrase "this should be on the shelves of every departmental library". I agree. For many this book would be of little interest and, for accountants, there should be a health warning because of the unflattering comparison made with economists on page 7 (a cause of much celebration with economically minded colleagues for whom Dr Kernick is a new hero). But I finish with an alternative cliché-"this should be required reading for everybody" making healthcare resource decisions at (primary and acute) trust, health authority and department levels.

T Wilson

Strategy Unit, Department of Health. London, UK; tim.wilson@doh.gsi.gov.uk

\section{An A-Z of Management for Healthcare Professionals}

Roy Lilley. Abingdon, Oxon: Radcliffe Medical Press, 2002. £19.95, 198 pp. ISBN 1857759532

There is a view that good management boils down to good common sense and that management books and courses just make the obvious explicit. It has also been noted that the trouble with common sense is that it is not all that common. Perhaps if it was we would not need management books and courses. At one end of the spectrum management books, particularly the more theoretical, can provide a turgid read or, like this one at the other, are full of practical tips. This book is entertaining and well written in plain English with a light hearted style. It is interactive with quotes and exercises. It is intuitive rather than systematic, well sprinkled with witty insights, and it is certainly not academic, comprehensive, or even evidence based.

Roy Lilley has done many things in his working life and, of these, his spell as Chairman of an NHS trust was the one he found most difficult to get to grips with. He well understands that healthcare management comes top of the list for complexity, difficulty, and frustration potential. He uses the 26 letters of the alphabet to give us his own highly introspective and idiosyncratic take on what he considers to be the 26 most important topics for managers. For example, $A$ is for Assertive, $L$ is for Leadership, and $S$ is for See outside the box. The alphabet format does make the text a bit stilted. For some letters there is a lot of text while, for others, the author seems to have run out of things to say. Between each letter there is a page with a single quote, most of which are about leadership such as "there are no office hours for leaders" - attributed to Cardinal Gibbons. The approach taken is very general, in some places to the point of vagueness and blandness. Curiously, there is virtually nothing very specific about health care itself, despite the title; the NHS is mentioned once or twice only, and it would have been helpful to have had more on healthcare management as there is a lot of specific material that is unique to the dilemmas involved in managing a healthcare system. Some topics are dealt with very briefly-for example, $J$ for Judgement has only one page and basically just says that judgement is the opposite of prejudice, so "don't be prejudiced" seems to be the message. The section on $L$ for Leadership is good, probably the best bit of the book, and the section on Difficult People and How to Deal with Them is useful and insightful.

This is an enjoyable and entertaining read, with some important messages and absolutely no jargon or "management speak". There is also plenty of empty space in the book, maybe to scribble your own notes. I recommend it.

D Mitchell

Chest and Allergy Clinic, St Mary's Hospital, London W2 INY, UK david.mitchell@st-marys.nhs.uk

\section{Using the Internet in Healthcare. 2nd Edition}

Stuart Tyrrell. Abingdon, Oxon: Raddliffe Medical Press, 2002. £19.95, 162 pp. ISBN 1857759974

The internet is an integral part of our health care system. This book will not replace the IT support staff or the hands-on computing course, but it will inform clinicians and administrators who want to gain confidence about using internet technologies in daily practice.
Stuart Tyrrell seeks to educate us about the internet. He provides overviews about what the internet is and how internet technologies such as intranets, e-mail, and the world wide web work using clear language and explanations. He demystifies web page design and addresses current issues such as the security and quality of online health information. Mike Ingham also authors a chapter outlining the role of the intranet as an organisational communications medium using an NHS case study.

The chapter entitled "Searching and Sifting" provides an excellent introduction for beginners searching the world wide web for health and non-health related information. Like most of this book, it is easy to read and will allay the fears of the most ardent technophobes. However, it lacks a discussion of health portals and will not meet the needs of clinicians or students wishing to undertake systematic literature reviews.

Although this is a valuable addition to the Harnessing Health Information Series, it is limited by its technological viewpoint. There is sparse discussion of the applications of internet technologies to improve healthcare delivery and services. For example, the concepts of e-commerce and SMS messaging in health care are introduced without reference to online pharmacies or the use of text messaging to improve medication compliance. There is little mention of telemedicine, online support groups, e-booking, e-health promotion, e-prescribing, or online clinical trials and research. Thus, it may fail to inspire those clinicians and administrators seeking ways to improve access to or efficiency of healthcare delivery in their own practices.

Stuart Tyrrell provides a short but limited discussion about the future implications of e-health technologies for the NHS, consumers, and healthcare providers. He mentions the potential e-health issues such as the globalisation of health care but does not elaborate on the potential effects on policies, costs, and outcomes. There is also no mention of guidelines for the exchange of clinical information between clinicians and consumers or the opportunity for shared clinical decision making and outcome monitoring.

In summary, if this book was a red wine I would describe it as "medium colour; well balanced with integrated fruit and oak; good weight and structure; overall soft and approachable; drink now". However, those readers seeking a more complex vintage will have to wait for the 3rd edition.

T L Bessell

Monash Institute of Health Services Research, Monash University, Clayton, Victoria 3168 , Australia; tracey.bessell@med.monash.edu.au

\section{CORRECTION}

In the paper entitled "A national survey of audit activity across the primary-secondary care interface" by $M$ Eccles, M Deverill, E McColl, and H Richardson which was published in Quality in Health Care 1996:5:193200 , the number of audits in column 1 of table 3 headed "Audit complete" should be 117, not 177. 